\title{
CONDUTA DO ENFERMEIRO FRENTE AOS CONFLITOS ÉTICOS E BIOÉTICOS EM ÁREA VULNERÁVEL NA ESF
}

\section{Patrícia Sônego Caetano}

Enfermeira; Universidade do Extremo Sul de Santa Catarina (UNESC), Criciúma (SC), Brasil.

\section{José Otávio Feltrin}

Enfermeiro; Mestrado em Saúde Coletiva; Docente do Curso de Enfermagem na Universidade do Extremo Sul de Santa Catarina (UNESC), Criciúma (SC), Brasil.

\section{Jacks Soratto}

Enfermeiro; Doutorado em Enfermagem; Docente do Curso de Enfermagem na Universidade do Extremo Sul de Santa Catarina (UNESC), Criciúma (SC), Brasil.

\section{Maria Tereza Soratto}

Enfermeira; Mestrado em Educação; Docente do Curso de Enfermagem do Curso de Enfermagem na Universidade do Extremo Sul de Santa Catarina (UNESC), Criciúma (SC), Brasil.

E-mail: guiga@unesc.net
RESUMO: Este estudo tem como objetivo identificar a conduta do enfermeiro frente aos conflitos éticos e bioéticos no atendimento de famílias em situação de vulnerabilidade social na Estratégia Saúde da Família (ESF). Pesquisa de abordagem qualitativa, descritiva, exploratória e de campo. Realizou-se uma entrevista semiestruturada com seis enfermeiros atuantes na ESF de áreas consideradas vulneráveis, em um município do extremo Sul de Santa Catarina. A análise dos dados foi realizada a partir da análise de conteúdo. A conduta dos enfermeiros para a resolução dos conflitos éticos e bioéticos envolve a linguagem clara e acessível com discussão de caso com a equipe multidisciplinar; o trabalho em rede; vínculo do agente comunitário de saúde (ACS) com a comunidade; e a conduta ética dos profissionais. Considera-se fundamental que os profissionais promovam discussões sobre os dilemas e conflitos éticos e bioéticos enfrentados, buscando a qualificação e a humanização do cuidado, com resolutividade da rede de serviços.

PALAVRAS-CHAVE: Bioética; Estratégia Saúde da Família (ESF); Ética em Enfermagem.

\section{NURSE'S BEHAVIOR IN THE WAKE OF ETHICAL AND BIOETHICAL CONFLICTS IN THE FAMILY HEATH STRATEGY}

\begin{abstract}
Current qualitative, descriptive, field and exploratory study identifies the nurse's behavior in the wake of ethical and bioethical conflicts in the attendance of socially vulnerable families within the context of Family Health Strategy. A half-structured interview was conducted with six nurses in Family Health Strategy in a municipality in the south of the state of Santa Catarina, Brazil. Data were analyzed according to contents. Nurses' behavior for the solution of ethical and bioethical conflicts involved clear and accessible language with case discussion with a multidisciplinary team; network; the health agent's bond with the community and the ethical behavior of the professionals. It is important that professionals discuss their dilemmas and ethical and bioethics conflicts towards more qualified and humanized care, coupled to solutions of service networks.
\end{abstract}

KEY WORDS: Bioethics; Ethics in Nursing; Family Health Strategy.

\section{INTRODUÇÃO}

A atenção primária à saúde representa um nível de atenção considerado capaz de mudar a realidade de saúde da comunidade 
(SOUZA JUNIOR; MISMITO; ARRUDA, 2012). A Atenção Básica considera o sujeito em sua singularidade, na complexidade, na integralidade e na inserção sociocultural e busca a promoção de sua saúde, a prevenção e tratamento de doenças e a redução de danos ou de sofrimentos que possam comprometer suas possibilidades de viver de modo saudável (BRASIL, 2012).

$\mathrm{Na}$ Atenção Básica podem surgir conflitos éticos e bioéticos relacionados à vulnerabilidade das famílias. Segundo a Resolução 466/12 vulnerabilidade está relacionada à redução da capacidade de autodeterminação da pessoa ou família (BRASIL, 2012). Vulnerabilidade social é caracterizada pelo envolvimento das famílias expostas a fatores de risco de natureza pessoal, social ou ambiental (PRATI; COUTO; KOLLER, 2009).

A Estratégia Saúde da Família constitui-se no primeiro contato da população com o serviço de saúde, devendo garantir "a resolubilidade de $85 \%$ dos problemas de saúde da população atendida e assegurar $\mathrm{o}$ atendimento especializado que requer maior complexidade tecnológica caso haja necessidade de encaminhamento aos demais níveis do sistema" (SOUZA JUNIOR; MISMITO; ARRUDA, 2012, p. 525).

Os problemas de saúde da população necessitam que a Estratégia Saúde da Família (ESF) organize redes de assistência integrada que contemplem as necessidades de cada área adstrita (DAUMAS, 2012). Com profissionais da saúde de diversas áreas, as equipes multidisciplinares da ESF enfrentam, na construção dos vínculos entre si e com as pessoas da coletividade, uma série de questões éticas, que podem passar despercebidas, deixando de ser identificadas (SIQUEIRA-BATISTA et al., 2015).

Os problemas e conflitos éticos relacionados ao sigilo e à confidencialidade das informações foram descritos em vários estudos na atenção básica (JUNGES et al., 2014; NORA; ZOBOLI; VIEIRA, 2015; SIQUEIRABATISTA et al., 2015). Estudos na área de ética ainda apontaram como problemas vivenciados na atenção básica a desigualdade de acesso aos serviços de saúde (SIQUEIRA-BATISTA et al., 2015); despreparo dos profissionais para trabalhar na atenção primária à saúde (JUNGES et al., 2014; NORA; ZOBOLI; VIEIRA, 2015); limites da interferência da equipe no estilo de vida da família e dos usuários com sentimento de impotência para convencer o usuário a dar continuidade ao tratamento (JUNGES et al., 2014).

Existem diferentes ordens de problemas éticos e bioéticos na ESF, destacando problemas éticos nas relações com usuários e família; nas relações da equipe; e nas relações com a organização e o sistema de saúde. Tais questões podem ser abordadas a partir de processos de educação continuada e de educação permanente, que poderão auxiliar os profissionais nos processos de construção do próprio conhecimento, o que se relaciona à capacidade de identificar questóes e de resolvê-las utilizando princípios e conceitos morais que possam sustentar as melhores decisões (SIQUEIRA-BATISTA et al., 2015).

Cada vez mais se exige uma formação cultural e moral na formação acadêmica e capacitação dos profissionais atuantes nas áreas de vulnerabilidade. Os conflitos éticos e morais no âmbito da atenção primária à saúde podem gerar uma dissociação do processo de trabalho e da integralidade da assistência à família (SIQUEIRA-BATISTA et al., 2015).

O código de ética rege o dever do profissional de Enfermagem prestar adequadas informações ao paciente e família a respeito da assistência de Enfermagem, possíveis benefícios, riscos e consequências que possam ocorrer; respeitar e reconhecer o direito do paciente em decidir sobre sua pessoa, seu tratamento e seu bem-estar (PIRES et al., 2013).

A efetivação da proposta da ESF necessita de um processo de reviravolta ética por exigir da equipe multiprofissional da atenção básica mudança atitudinal e cultural. A ESF reforça a necessidade da sensibilidade e compromisso ético (ZOBOLI, 2007).

Desta forma, constata-se a necessidade de mudança no paradigma da saúde, não mais centrado no modelo hospitalacêntrico, mas, na promoção e intervenção na qualidade de vida das famílias. Nesta perspectiva, a assistência de Enfermagem deve ser uma prática sustentada pela humanização do cuidado, com o exercício pleno de cidadania, respeito à dignidade e liberdade. Na concepção de que as condições de vida definem o processo saúde-doença-cuidado das famílias, o enfermeiro deve ter uma prática transformadora para buscar a promoção da saúde a partir da autonomia das famílias (ZOBOLI, 2007). 
Diante de tal complexidade, justifica-se este estudo percebendo a importância do profissional de saúde estar ampliando sua qualificação técnica e ética para trabalhar em áreas vulneráveis. O presente estudo teve como objetivo identificar a conduta do enfermeiro frente aos conflitos éticos e bioéticos no atendimento de famílias em situação de vulnerabilidade social na Estratégia Saúde da Família (ESF).

\section{MATERIAL E MÉTODOS}

Pesquisa de abordagem qualitativa, descritiva, exploratória e de campo. O estudo foi desenvolvido em um município do extremo Sul de Santa Catarina. Aplicouse entrevista semiestruturada com seis enfermeiros atuantes na ESF de áreas consideradas vulneráveis, nos meses de abril e maio de 2016.

A análise dos dados foi realizada a partir da análise de conteúdo, com a categorização dos dados, através da ordenação, classificação e análise final dos dados pesquisados. Categorizar é agrupar elementos, ideias ou expressões em torno de um conceito, abrange elementos ou aspectos com características comuns ou que se relacionam entre si, são estabelecidas para classificar os eventos (MINAYO, 2009). Na pesquisa foram identificadas cinco categorias: concepção de ética e bioética; capacitação dos profissionais da ESF relacionados à ética e bioética no atendimento de famílias em situação de vulnerabilidade social; os conflitos éticos e bioéticos que permeiam o processo de trabalho do enfermeiro no atendimento de famílias em situação de vulnerabilidade social; os desafios enfrentados pelo enfermeiro na gestão de pessoas; a conduta do enfermeiro para a resolução dos conflitos éticos e bioéticos no atendimento de famílias em situação de vulnerabilidade social.

Para preservar o sigilo decorrente das entrevistas realizadas, de acordo com as diretrizes e normas regulamentadoras da Resolução 466/12 que envolvem pesquisa com Seres Humanos e Grupos Vulneráveis, utilizou-se a letra "E" para os enfermeiros, seguida do respectivo número - E1 a E6. A pesquisa foi aprovada pelo Comitê de Ética em Pesquisa da UNESC, conforme parecer $\mathrm{n}^{0} 1.466 .454$.

\section{RESULTADOS}

\subsection{PERFIL DOS ENFERMEIROS ATUANTES NA ESF}

Em relação ao perfil dos enfermeiros entrevistados, cinco são do sexo feminino e um do sexo masculino, a idade variou de 23 anos a 42 anos. O tempo de atuação na área da saúde variou de 03 a 12 anos; o tempo de atuação como enfermeiro variou de 06 meses a 12 anos e o tempo de atuação na ESF variou de 3 a 12 anos. Os enfermeiros são especializados em: Auditoria (E2); Gestão Hospitalar e Auditoria em Saúde e Obstetrícia (E5); Saúde Coletiva (E6). Os enfermeiros E3 e E4 estão atualmente cursando a especialização em Estomaterapia. O enfermeiro E1 não possui especialização.

\subsection{CONCEPÇÃO DE ÉTICA E BIOÉTICA}

As questões éticas têm sido alvo de muitas discussões nos últimos anos, sendo realizadas em diversos espaços da sociedade. As respostas dos enfermeiros denotam que a ética é concebida como um conjunto de regras, que regem um código de conduta, baseado em princípios e valores morais.

E1 - "Pensa-se que a ética é um conjunto de regras que norteia a moral do sujeito frente aos conflitos do cotidiano. Bioética é o mesmo conjunto mas voltado para a área da saúde."

E2 - "Ética é o 'parar para pensar', a responsabilidade em sua competência, elegendo decisões para a prática profissional. Bioética é o conbecimento teórico da profissão a ser seguida."

E3 - "Ética é um código de conduta padrão universal, mediante a qualquer atividade de trabalbo. Bioética é o código de conduta aplicado a ciências biológicas em geral."

E4 - "Ética tem relação com o comportamento bumano, seus valores e princípios como agir perante o outro, compromissos e deveres morais. Bio refere ao conbecimento biológico, então tem relação com tudo que se refere aos seres tratados de forma ética, ou seja, levando em consideração valores e princípios morais."

E5 - "A Ética está relacionada ao caráter, busca através da fundamentação teórica o melbor modo de viver, de conviver em sociedade. Abrange 
diversos campos, como sociologia, pedagogia, política, psicologia, entre outros. Bioética é o estudo transdisciplinar entre ciências biológicas da saúde, filosofia e direito que investiga as condições necessárias para uma administração responsável da vida bumana animal e ambiental."

E6 - "São bons hábitos que contribuem para que a pessoa tome atitudes justas, com respeito, igualdade, respeitando a dignidade das pessoas e também que seja solidário."

\subsection{CAPACITAÇÃO DOS PROFISSIONAIS DA ESF RELA- CIONADOS À ÉTICA E BIOÉTICA NO ATENDIMEN- TO DE FAMÍLIAS EM SITUAÇÃO DE VULNERABILI- DADE SOCIAL}

A capacitação do enfermeiro para atuação ética e bioética no atendimento de famílias em situação de vulnerabilidade social foi adquirida no curso de graduação ou especialização, segundo os enfermeiros E2, E4 e E5. Os enfermeiros E1, E3 e E6 não receberam capacitação voltada à temática pesquisada:

\section{E2 - "Apenas na Universidade."}

E4 - "Durante a Graduação tal assunto foi abordado diversas vezes."

E5 - "Não. Somente assuntos abordados na Graduação e Especializações em relação a éticabioética."

E1; E3; E6 - "Não."

A equipe da ESF não recebeu capacitação relacionada à ética-bioética no atendimento de famílias em situação de vulnerabilidade social, segundo o relato dos enfermeiros:

\section{E1 - "Não teve."}

E2 - "Neste município não bouve nenbuma ainda."

\section{E6 - "Nunca fui capacitada."}

E5 - "Não há capacitação dos profissionais relacionados a ética-bioética no atendimento de famílias em situações de vulnerabilidade. Existe comprometimento da equipe em reconbecer essas famílias em situação vulnerável para acompanhamento e intervenção através de reunião de equipe."

Ressalta-se no relato do enfermeiro E5 a importância do comprometimento da equipe para atuação com famílias em situação de vulnerabilidade social, que necessita de diálogo com a equipe multiprofissional para a tomada de decisão em relação à intervenção em cada caso.

O enfermeiro E3 não soube responder a questão e o enfermeiro E4 ressaltou o déficit na capacitação abordando o assunto, sendo que a abordagem da temática deveria ser feita de forma específica para cada categoria profissional:

\section{E3 - "Não sei."}

E4 - "Acredito que seja falba, pois esse assunto deveria ser retornado mais vezes, com abordagens diferentes para cada classe profissional."

3.4 OS CONFLITOS ÉTICOS E BIOÉTICOS QUE PERMEIAM O PROCESSO DE TRABALHO DO ENFERMEIRO NO ATENDIMENTO DE FAMÍLIAS EM SITUAÇÃO DE VULNERABILIDADE SOCIAL

Os conflitos éticos e bioéticos que permeiam o processo de trabalho do enfermeiro no atendimento às famílias em situação de vulnerabilidade estão relacionados principalmente ao sigilo profissional (E2; E5; E6):

E2 - "Temos problemas por manter a ética, pois trabalhamos com profissionais que também são residentes no bairro, sendo assim os problemas dos pacientes se transformam muitas vezes em problemas de pessoas próximas como familiares, vizinbos, amigos. Havendo a dificuldade de sigilo e consequentemente ética."

E5 - "Limite da interferência da equipe no estilo de vida da família e do usuário. Falta de adesão aos encaminhamentos por parte do usuário. Rotatividade da equipe e falta de mão de obra para acompanbar essas famílias. Perda de vínculo por rotatividade e defasagem da equipe. Dificuldade por parte de alguns membros da equipe em manter sigilo profissional." 
E6 - "Principalmente o sigilo. Muitas situações são necessárias compartilhar com demais integrantes da equipe para que seja solucionado. Acolbimento nem sempre é possível escutar o paciente devido à sobrecarga e falta de funcionários."

Além das questões que envolvem o sigilo, a perda do vínculo com a família em decorrência da rotatividade e defasagem da equipe multiprofissional (E5); as dificuldades inerentes ao acolhimento qualificado em virtude da sobrecarga de trabalho e a falta de estrutura física (E6) para o atendimento das famílias em situação vulnerável foram citados como conflitos éticos e bioéticos que permeiam o processo de trabalho do enfermeiro.

As dificuldades inerentes ao processo de trabalho na ESF, relacionadas à falta de profissional e à realização de atividades que não competem ao enfermeiro dificultam o exercício da autonomia do profissional, segundo o enfermeiro E4:

E4 - "Autonomia. Muitas vezes nos vemos realizando diversas atividades que nem sempre comportam a nossa classe profissional, em decorrência da necessidade dos pacientes e falta de profissional."

A gestão do serviço de saúde incorporando coordenadores sem formação específica, em virtude das questões de indicação política, além de profissionais desmotivados, desinteressados, com falta de capacitação técnica, são conflitos éticos e bioéticos que permeiam o processo de trabalho frente ao atendimento das famílias em situação vulnerável, citado no relato do enfermeiro E3:

E3 - "Ser administrado-chefiado por alguém sem formação na área ou por cargo político. Profissionais antigos viciados na mesma conduta, sem reciclagem ou educação continuada, desinteresse, falta de estímulo $e$ incentivo causado por má gestão administrativa."

A situação de vulnerabilidade da ESF com famílias envolvidas no tráfico de drogas, violência e gravidez na adolescência foram questões citadas na fala do enfermeiro E1:
E1 - "Tráfico de drogas, violência contra a mulber e a criança, gravidez na adolescência."

\subsection{OS DESAFIOS ENFRENTADOS PELO ENFERMEIRO NA GESTÃO DE PESSOAS}

O maior desafio enfrentado pelos enfermeiros no processo de trabalho no atendimento de famílias em situação de vulnerabilidade social está relacionado à resolutividade da rede de apoio:

E1 - "Fazer com que a equipe entenda que cada indivíduo tem a sua singularidade, assim como os profissionais também têm (Equipe). O não funcionamento na rede de apoio do ESF."

E2 - "Temos dificuldades a tratamento (longo prazo), como internações para pacientes com dependência de drogas ou problemas psiquiátricos."

E6 - "Muitos serviços não respondem, não devolvem a contra referência. Saber lidar com as personalidades, tem pessoas que não têm boas atitudes, é do próprio perfil. A própria população é difícil de trabalhar, muitos sabem seus direitos, mas não sabem seus deveres."

Os enfermeiros E1 e E6 ressaltaram que cada pessoa possui sua singularidade, sendo que a equipe deve compreender estas diferenças e promover um cuidado qualificado conforme cada caso. O enfermeiro E4 ressaltou a falta de motivação dos profissionais:

\section{E4 - "Falta de profissionais interessados."}

O enfermeiro E5 relatou novamente as questões que envolvem a rotatividade e falta de profissionais, além da falta de adesão do paciente ao tratamento:

E5 - "Rotatividade profissional e déficit de profissionais. Falta de adesão ao tratamento por parte dos usuários."

No processo de trabalho da ESF os enfermeiros não recebem um suporte adequado, com falta de segurança legal, proteção ou colaboração da gestão, segundo o enfermeiro E3: 
E3 - "Enfermeiros do ESF não são ouvidos, apenas designados a cumprir metas designadas da gestão. Não há segurança legal, proteção ou colaboração por parte da gestão. Recentemente o novo secretário de saúde assumiu, porém está sendo mal assessorado. Risco social e vulnerabilidade são relacionados pela gestão, que despreza um dos princípios básicos do SUS, que é a equidade."

\subsection{A CONDUTA DO ENFERMEIRO PARA A RESOLUÇÃO DOS CONFLITOS ÉTICOS E BIOÉTICOS NO ATEN- DIMENTO DE FAMÍLIAS EM SITUAÇÃO DE VULNE- RABILIDADE SOCIAL}

As dificuldades inerentes ao processo de trabalho em área vulnerável para a tomada de decisão, denúncia e preservação do sigilo ficaram visíveis nos relatos dos enfermeiros E1 e E2:

E1 - "Já tomei condutas como a denúncia, que boje já não denuncio mais, porém quando existe o envolvimento com crianças aciono. Ficamos muito vulneráveis, assim dificulta o desenvolvimento do nosso trabalbo na comunidade. Porque o sigilo não é preservado."

E2 - "Infelizmente trabalhamos em área de risco tornando-se assim ainda mais dificultoso o acesso a essas famílias, pois muitas vezes não podemos acionar outras instituições que poderiam contribuir para resolução de casos de vulnerabilidade, dificultando assim os atendimentos."

Segundo o enfermeiro E3 é essencial uma linguagem clara e acessível para a resolução dos conflitos éticos e bioéticos no atendimento de famílias em situação de vulnerabilidade social:

\section{E3 - "Ter uma linguagem acessivel."}

A importância do trabalho em rede para a resolução dos conflitos éticos e bioéticos no atendimento de famílias em situação de vulnerabilidade social, além do trabalho realizado pelos Agentes Comunitários de Saúde (ACS), que mantêm maior vínculo com as famílias, foi citado na fala do enfermeiro E6:
E6 - "Manter parceria com a assistente social e com o Centro de Referência da Assistência Social CRAS. Manter maior contato com ACS que possui maior vínculo."

A conduta ética amparada pelo código de ética foi citada pelo enfermeiro $\mathrm{E} 4$ como o principal meio para a resolução dos conflitos vivenciados no dia a dia nos atendimentos de famílias em situação de vulnerabilidade social:

E4 - "Agir conforme o código de ética da minha profissão e também eticamente como ser bumano. Devemos agir com responsabilidade, postura profissional, avaliando cada situação."

Considera-se imprescindível a discussão dos casos pela equipe com o reconhecimento da vulnerabilidade social vivenciada pelas famílias, buscando a humanização do cuidado dos cidadãos de direito:

E5 - "Discussão de caso com a equipe multidisciplinar, reconbecimento das famílias e áreas vulneráveis, para prestação de serviço e educação em saúde. Discutir sobre ética e bioética com a equipe multidisciplinar. Formar equipe que exerçam uma atuação profissional marcada pela bumanização, pelo cuidado, pelo exercício da cidadania e alicerçada bá compreensão de que as condições de vida definem o processo saúde-doença das famílias."

\section{DISCUSSÃO}

A ética está relacionada à experiência da morada humana, compreendendo uma teia de relação interpessoal e interprofissional, orientando-se por princípios, convicções e valores sociais consagrados. Ser ético requer uma percepção de si, do meio e dos outros, envolvendo sabedoria, consciência, conhecimento, razão, comunicação, interação, valores e cultura, liberdade e responsabilidade, além da vontade de possibilitar abertura para o outro (FREITAS; OGUISSO; FERNANDES, 2010). 
A bioética relaciona-se aos problemas éticos e morais que emergem da ação humana em todos os níveis da atenção à saúde. A reflexão sobre bioética requer o auxílio de conceitos fundamentais da ética, sendo que os aspectos éticos da atenção à saúde nem sempre são visíveis aos gestores, usuários e trabalhadores da área da saúde e, ao final, interferem na consolidação do Sistema Único de Saúde (SUS) (VIDAL et al., 2014).

A concepção de ética e bioética dos enfermeiros denota a necessidade da reflexão sobre as ações e comportamentos individuais e coletivos para o aprimoramento da conduta ética profissional. Observouse por meio das entrevistas com os enfermeiros o déficit na capacitação dos profissionais da ESF relacionados à ética e bioética no atendimento de famílias em situação de vulnerabilidade social.

A bioética realiza uma reflexão multidisciplinar sobre os principais dilemas e conflitos éticos que a humanidade vivencia, tendo como objetivo a humanização dos serviços de saúde, a concepção do cidadão de direito e a reflexão sobre ética, tecnologia, meio ambiente, pobreza e vulnerabilidade

Os aspectos éticos e bioéticos integrantes do cotidiano do cuidar na ESF muitas vezes não são percebidos, resultando em danosàatenção, especialmente no que se refere ao vínculo e corresponsabilização pela saúde. Para atuar na saúde da família o profissional, além de redirecionar sua prática clínica, precisa redimensionar sua sensibilidade para perceber, compreender $\mathrm{e}$ ponderar acerca de situações eticamente significativas ou problemáticas. Existe a necessidade de educação continuada com direcionamento para a formação de especialistas em saúde da família objetivando a humanização do cuidado (LIMA et al., 2014).

A relação que permeia os profissionais e o usuário não deve se restringir apenas ao tratamento das doenças, mas se fundamentar na promoção da saúde e na percepção do indivíduo como ser único, que necessita ser escutado e compreendido nas necessidades físicas, emocionais e sociais (LIMA et al., 2014).

Os profissionais devem ser engajados em discussões de temas éticos que emergem das situações de trabalho, proporcionado um ambiente assistencial colaborativo e de excelência técnica e moral. Dessa forma há a possibilidade de garantir espaços de escuta e de reflexão sobre as questões éticas e seus determinantes, assim como atividades educativas sistemáticas abordando a temática (SANTOS et al., 2008), objetivando a resolução prudente e responsável dos problemas éticos (NORA; ZOBOLI; VIEIRA, 2015).

$\mathrm{Na}$ estratégia da saúde da família (ESF), desafios relacionados à ética e bioética poderão surgir, portanto é indispensável a capacitação para as equipes atuantes nessas áreas. Na ESF, a proximidade do profissional ao ambiente familiar propicia um contato mais próximo com o usuário permitindo ações educativas condizentes com a realidade vivenciada pela comunidade. A proposta de ação educativa não se resume a uma nova configuração da equipe, mas a um novo processo de trabalho marcado pela ética e bioética, humana e vinculada ao exercício da cidadania (LIMA et al., 2014). Sendo assim percebese a necessidade da capacitação para os profissionais, abordando os temas relacionados à ética e bioética, reforçando a autonomia e o agir com competência ética.

Os conflitos éticos e bioéticos relacionados ao processo de trabalho do enfermeiro no atendimento de famílias em situação de vulnerabilidade social são caracterizados principalmente pelas questões que envolvem o sigilo profissional; falta de recursos humanos e de estrutura física; perda de vínculo por rotatividade e defasagem da equipe; falta de adesão aos encaminhamentos por parte do usuário e o estilo de vida das famílias; autonomia do enfermeiro; gestão do serviço de saúde; perfil do profissional atuante na ESF e a vulnerabilidade social das famílias.

O código de ética de Enfermagem em relação ao sigilo profissional no Art. 82 cita como responsabilidades e deveres: manter segredo sobre fato sigiloso de que tenha conhecimento em razão de sua atividade profissional, sendo que segundo o Art. 83 cabe ao enfermeiro orientar a equipe sob sua responsabilidade, sobre o dever do sigilo profissional (PIRES et al., 2013).

O código de ética de Enfermagem no artigo Art. 81 preceitua como dever do profissional de Enfermagem a proibição de revelar informações confidenciais de que tenha conhecimento em razão de seu exercício profissional a pessoas ou entidades que não estejam obrigadas ao sigilo (PIRES et al., 2013). 
Lidar com o sigilo e a confidencialidade das informações é aspecto que deve permear todo o cotidiano do trabalho das equipes da atenção básica, buscando definir em que medida as informações privativas do paciente devem ser compartilhadas no âmbito da equipe (SIQUEIRA-BATISTA et al., 2015).

A falta de apoio estrutural para discutir e resolver os problemas éticos nos serviços de saúde e a carência de estrutura física foi identificado como fator gerador de conflitos éticos na pesquisa de Nora, Zoboli e Vieira (2015), também identificado nesta pesquisa. É necessário fazer uma reflexão e identificar as perspectivas e desafios futuros vinculados ao processo de trabalho na ESF. É preciso ter resolutividade sobre as questões estruturais e estratégicas na atenção básica, tais como: gestão, gerência, financiamento, planejamento, recursos humanos, participação da comunidade e incorporação tecnológica (OLIVEIRA, 2013).

A vulnerabilidade social das famílias com envolvimento no tráfico de drogas, violência e a gravidez na adolescência foram destacados como um dos conflitos éticos e bioéticos relacionados ao processo de trabalho do enfermeiro da ESF.

As violências são caracterizadas pelo uso intencional da força física ou do poder, real ou em ameaça, contra si próprio, contra outra pessoa, ou contra um grupo ou comunidade que possa resultar em morte, lesão, dano psicológico, problemas de desenvolvimento ou privação. A violência relaciona-se à determinação social, política e econômica e o avanço na definição dos direitos humanos, sendo necessário identificá-la como um problema prioritário de saúde (BRASIL, 2008).

O uso de substâncias químicas é considerado um problema social e de saúde pública. O uso de droga é um dos principais problemas de saúde pública em todo o mundo, considerado um problema social (COUTINHO; SILVA et al., 2015; FERREIRA; MACHADO, 2013). A equipe da ESF tem um papel importante no rastreamento, tratamento e prevenção do uso de drogas ou álcool (FERREIRA; MACHADO, 2013).

A gravidez na adolescência caracteriza-se como um processo de perdas e oportunidades (FARIAS; MORE, 2012). Os fatores de risco para a gravidez na adolescência são de ordem biológica, psicossocial, cultural e econômica (FARIAS; MORE, 2012; PARIZ; MENGARDA; FRIZZO, 2012). A vulnerabilidade social pode favorecer a ocorrência da gravidez em virtude da baixa escolarização, relações familiares violentas ou conflituosas, ausência ou insuficiência de recursos financeiros e serviços de saúde, além de poucas perspectivas profissionais e de futuro (FARIAS; MORE, 2012; PARIZ; MENGARDA; FRIZZO, 2012; NERY et al., 2015).

No Brasil, muitas famílias convivem com problemas de subsistência e de vulnerabilidade social. Dificuldades econômicas encontram-se associadas a fatores de desemprego, problemas habitacionais e de saneamento, baixa escolaridade, famílias com maior número de crianças e dependentes, dificuldades de acesso à saúde e recursos comunitários, presença de situações de violência (SCHLITHLER; CERON; GONÇALVES, 2016).

Trabalhar com família é desafiador. A relação entre profissional-usuário na ESF é permeada por diversos aspectos que envolvem situações de violência $\mathrm{e}$ vulnerabilidade social. O enfermeiro deve estar preparado para identificar, acolher e promover um cuidado qualificado e humanizado com as famílias possibilitando a criação de vínculo e confiança.

Segundo os enfermeiros entrevistados os desafios enfrentados na gestão de pessoas configuramse nas dificuldades inerentes à resolutividade da rede de serviços; lidar com as diferenças; falta de interesse e motivação da equipe com rotatividade e falta de profissionais; falta de segurança para o trabalho em áreas vulneráveis e falta de adesão do usuário ao tratamento prescrito.

Estudo de revisão de Nora; Zoboli; Vieira (2015) demonstrou que os enfermeiros têm pouca educação ética na sua formação inicial, com situações de despreparo e falta de perfil dos profissionais para trabalhar na Atenção Primária de Saúde (APS).

O número reduzido de profissionais e as constantes trocas entre os membros das equipes geram problemas éticos, pois é proporcionada uma atenção insuficiente à necessidade do usuário. $\mathrm{O}$ respeito à autonomia do usuário é elemento fundamental da relação enfermeiro-usuário, sendo que a recusa dos usuários para seguirem as orientações dos profissionais ou não aceitação do serviço que lhe é oferecido é considerado 
um problema ético encontrado na Atenção Primária de Saúde - APS (NORA; ZOBOLI; VIEIRA, 2015).

Odireitoàinformaçãoéconsideradofundamental para a autonomia na tomada de decisão, sendo que a adesão do usuário ao tratamento requer a humanização e a ética do cuidado, com o estabelecimento de uma relação de confiança, vínculo e co-responsabilização entre o enfermeiro da ESF e a família (NORA; ZOBOLI; VIEIRA, 2015).

Percebe-se desta forma o quanto são variados os problemas enfrentados pelos enfermeiros que atuam na ESF, que envolvem não somente as questões de enfrentamento da vulnerabilidade das famílias atendidas na ESF, mas todo o processo de trabalho e a gestão do serviço para a resolutividade destes desafios.

$\mathrm{Na}$ categoria sobre a conduta do enfermeiro para a resolução dos conflitos éticos e bioéticos no atendimento de famílias em situação de vulnerabilidade social tornam-se visíveis as dificuldades que o enfermeiro enfrenta quando precisa denunciar um caso e vivencia conflitos relacionados à própria vulnerabilidade do profissional que atua nestas áreas, onde pode ocorrer quebra de sigilo e consequentemente represálias ao denunciante. O que fazer neste caso, calar e omitir? Colocar-se em perigo ou defender-se? Qual a proteção legal que as instituições podem ofertar ao profissional que trabalha em áreas vulneráveis?

Em estudo de Nora, Zoboli e Vieira (2015) sobre os problemas éticos vivenciados por enfermeiros na atenção primária à saúde ressaltaram dificuldades inerentes às informações sigilosas e as potenciais ameaças à privacidade e confidencialidade das informações, corroborando os resultados desta pesquisa.

O reconhecimento de uma situação dilemática é uma etapa importante na constituição do sujeito e profissional ético. Os profissionais de saúde se deparam com dilemas e conflitos advindos das relações de poder, diante das quais se perguntam se devem calar ou falar, optar pela omissão ou reagir, participar ou ficar indiferentes (SANTOS et al., 2008).

Ainda segundo os enfermeiros entrevistados a conduta alicerçada para a resolução dos conflitos éticos e bioéticos envolve a linguagem clara e acessível com discussão de caso com a equipe multidisciplinar, o trabalho em rede e vínculo do Agente Comunitário de Saúde com a comunidade e a conduta ética dos profissionais que atuam em área de vulnerabilidade social.

O Agente Comunitário de Saúde - ACS é um articulador do processo de trabalho da equipe da ESF, por morar na sua área de atuação, conhecer a comunidade $\mathrm{e}$ ter maior acesso aos domicílios. O ACS é mediador entre a equipe profissional e a comunidade configurando-se como um elo entre as necessidades de saúde das famílias e o que pode ser feito para a melhoria das condições de vida da comunidade (LOPES et al., 2012; LOURENÇÃO et al., 2012; MACHADO, 2015; PICCININI; SILVA, 2015; SANTOS; FARIAS FILHO, 2016; TOLOMEU et al., 2013).

A comunicação qualificada entre a equipe de Enfermagem e usuário poderia reduzir conflitos éticos na atenção básica e favorecer a condução satisfatória de uma relação terapêutica e ética (NORA; ZOBOLI; VIEIRA, 2015).

O código de ética dos profissionais de Enfermagem considera a necessidade e o direito de assistência em Enfermagem da população, aos interesses do profissional e de sua organização. Está centrado na individualidade e coletividade e pressupõe que os trabalhadores de Enfermagem estejam aliados aos usuários na luta por uma assistência sem risco e acessível a todos (PIRES et al., 2013).

Nos diferentes cenários de saúde, as questões bioéticas estão cada vez mais presentes no dia a dia, fazendo com que os profissionais reflitam e atuem sobre a melhor conduta a ser tomada em situação de conflito. O diálogo, a comunicação e a reflexão interdisciplinar são os meios fundamentais para dar suporte à tomada de decisão, entretanto, as grandes demandas, aliadas à falta de estrutura física e de trabalho adequada dos profissionais, comprometem o desenvolvimento de uma conduta embasada nos princípios éticos e bioéticos (SANTOS et al., 2008).

"As situações de conflitos éticos e bioéticos enfrentados no âmbito da atenção primária à saúde impossibilitam a promoção da integralidade do cuidado" (SIQUEIRA-BATISTA et al., 2015, p. 113), o que requer medidas que possibilitem a reflexão dos casos, a educação em ética e uma rede de saúde e gestão dos serviços 
qualificada e eficaz, para suprir as necessidades das ESF que assistem às famílias em situação de vulnerabilidade social.

Estabelecer iniciativas de educação continuada em ética pode despertar a atenção dos profissionais para os problemas vivenciados no processo de trabalho, levando ao desenvolvimento de competência ética (NORA; ZOBOLI; VIEIRA, 2015). O desenvolvimento da competência ética está sempre em construção, sendo que a reflexão e ação embasada nos princípios primordiais da ética e da bioética devem estar inseridos no âmbito do ensino e na prática (SCHAEFER; JUNGES, 2014). A ética pressupõe a atenção individualizada pautada no respeito mútuo, na interação e na humanização do cuidado à família (NORA; ZOBOLI; VIEIRA, 2015). Os enfermeiros precisam de apoio para o enfrentamento dos problemas éticos e o aprimoramento do desenvolvimento da competência ética, para lidar com os problemas éticos e bioéticos com a escuta e diálogo permanente com a família (NORA; ZOBOLI; VIEIRA, 2015, p. 117).

\section{CONSIDERAÇÕES FINAIS}

A conduta dos enfermeiros para a resolução dos conflitos éticos e bioéticos envolve a linguagem clara e acessível com discussão de caso com a equipe multidisciplinar, o trabalho em rede e vínculo do ACS com a comunidade e a conduta ética dos profissionais que atuam em área de vulnerabilidade social. Considerase imprescindível a capacitação da equipe relacionada aos conflitos éticos e bioéticos vivenciados em área vulnerável na Estratégia Saúde da Família e a conduta ética requerida nestes casos. É fundamental que a equipe de Enfermagem promova discussões sobre os dilemas e conflitos éticos e bioéticos enfrentados, buscando a qualificação e a humanização do cuidado, com resolutividade da rede de serviços.

A pesquisa demonstrou claramente as dificuldades da equipe frente à resolutividade dos casos em área de vulnerabilidade social, o que requer uma rede de atenção qualificada e eficaz, equipe multiprofissional capacitada, comunicação eficaz entre a rede, preservação do sigilo e privacidade das informações e humanização do cuidado às famílias.

\section{REFERÊNCIAS}

SIQUEIRA-BATISTA, R.; GOMES, A. P.; MOTTA, L. C. S.; RENNÓ, L.; LOPES, T. C.; MIYADAHIRA, R.; VIDAL, S. V.; COTTA, R. M. M. (Bio)ética e Estratégia Saúde da Família: mapeando problemas. Saúde soc. São Paulo, v. 24, n. 1, p. 113-128, mar. 2015. Disponível em: <http://www. scielo.br/scielo.php?script $=$ sci_arttext\&pid $=$ S0104$12902015000100113 \& \operatorname{lng}=$ en\&nrm $=$ iso $>$. Acesso em: 28 nov. 2015. http://dx.doi.org/10.1590/S010412902015000100009 .

BRASIL. Ministério da Saúde. CONASS. Conselho Nacional de Secretários de Saúde. O desafio do enfrentamento da violência: situação atual, estratégias e propostas. Brasília: Ministério da Saúde, 2008. 61p.

BRASIL. Conselho Nacional de Saúde. Resolução no 466, de 12 de dezembro de 2012. Disponível em: < http:// conselho.saude.gov.br/resolucoes/2012/Reso466.pdf> Acesso em: 13 set. 2015.

BRASIL. MinistériodaSaúde. Secretaria deAtençãoà Saúde. Departamento de Atenção Básica. Política Nacional de Atenção Básica. Brasília: Ministério da Saúde, 2012, 110p. Disponível em: < http://189.28.128.100/dab/docs/ publicacoes/geral/pnab.pdf> . Acesso em: 25 jan. 2016.

COUTINHO E SILVA, I. F.; SOUZA, K. S.; BATISTA, S. H. R.; ALMEIDA, R. J. Serviços de saúde e comunidades terapêuticas: há uma relação em prol do dependente químico?. Saúde e Pesqui., v. 8, n. 3, p. 533-540, set./ dez. 2015.

DAUMAS, J. S. P. As dificuldades enfrentadas pela estratégia saúde da família no cuidado à saúde do dependente químico. 2012. 78 f. Dissertação (Mestrado em Saúde da Família) - Universidade Estácio de Sá, Rio de Janeiro, 2012. Disponível em: < http://portal.estacio.br/ media/4258930/jane\%20do\%20socorro\%20pantoja\%20 daumas.pdf > . Acesso em: 25 jan. 2016.

FARIAS, R.; MORE, C. O. O. Repercussões da gravidez em adolescentes de 10 a 14 anos em contexto de vulnerabilidade social. Psicol. Reflex. Crit., Porto Alegre, v. 25, n. 3, p. 596-604, 2012. Disponível em: < http://www. 
scielo.br/scielo.php?script $=$ sci_arttext\&pid $=$ S0102$79722012000300020 \& \operatorname{lng}=$ en $\& n r m=$ iso $>. \quad$ Acesso em: 24 jul. 2016. http://dx.doi.org/10.1590/S010279722012000300020 .

FERREIRA, S. C.; MACHADO, R. M. Equipe de Saúde da Família e o uso de drogas entre adolescentes. Cogitare Enferm., v. 18, n. 3, p. 482-9, jul./set. 2013.

FREITAS, G. F.; OGUISSO, T.; FERNANDES, M. F. P. Fundamentos éticos e morais na pratica de Enfermagem. Enferm. Foco, v. 1, n. 3, p. 104-108, 2010.

JUNGES, J. R.; ZÓBOLI, E. L. C. P.; SCHAEFER, R.; NORA, C. R. D.; BASSO, M. Validação da compreensibilidade de um instrumento sobre problemas éticos na atenção primária. Rev. Gaúcha Enferm. Porto Alegre, v. 35, n. 1, p. 148-156, mar. 2014. Disponível em: <http://www. scielo.br/scielo.php?script $=$ sci_arttext\&pid $=$ S1983$14472014000100148 \& \operatorname{lng}=$ en\&nrm $=$ iso $>$. Acesso em: 16 jan. 2016. http://dx.doi.org/10.1590/19831447.2014.01.39811.

LIMA, C. A.; OLIVEIRA, A. P. S.; MACEDO, B. F.; DIAS, O. V.; COSTA, S. M. Relação profissional-usuário de saúde da família: perspectiva da bioética contratualista. Rev. Bioét. Brasília, v. 22, n. 1, p. 152-160, abr. 2014. Disponível em: $\quad<$ http://www.scielo.br/scielo.php?script $=$ sci arttext\&pid $=$ S1983-80422014000100017\&lng $=$ en \& $\mathrm{nrm}=$ iso $>$. Acesso em: 09 jun. 2016. http://dx.doi. org/10.1590/S1983-80422014000100017.

LOPES, D. M. Q.; BECK, C. L. C.; PRESTES, F. C.; WEILLER, T. H.; COLOMÉ, J. S.; SILVA, G. M. Agentes Comunitários de Saúde e as vivências de prazer - sofrimento no trabalho: estudo qualitativo. Rev. esc. enferm. USP, São Paulo, v. 46, n. 3, p. 633-640, jun. 2012. Disponível em: $\quad<$ http://www.scielo.br/scielo.php?script $=$ sci arttext\&pid $=$ S0080-62342012000300015\&lng $=$ en\& $\mathrm{nrm}=$ iso $>$. Acesso em: 04 ago. 2016. http://dx.doi. org/10.1590/S0080-62342012000300015.

LOURENÇÃO, L. G.; BACK, C. R.; SANTOS, C. B.; SOUSA, C. P. Qualidade de vida de agentes comunitários de saúde de um município do interior do Estado de São Paulo. Arq.Ciênc.Saúde, v. 19, n., p. 19-27, jan./mar. 2012.
MACHADO, L. M. Estratégia Saúde da Família: a percepção do agente comunitário de saúde quanto a sua atuação. Cienc Cuid Saude, v. 14, n. 2, p. 1105-1112, abr./jun. 2015.

MINAYO, M. C. S. Pesquisa social: teoria, método e criatividade. 28. ed. Petrópolis: Vozes, 2009. 108 p.

NERY, I. S.; GOMES, K. R. O.; BARROS, I. C.; GOMES, I. S.; FERNANDES, A. C. N.; VIANA, L. M. M. Fatores associados à reincidência de gravidez após gestação na adolescência no Piauí, Brasil. Epidemiol. Serv. Saúde, Brasília, v. 24, n. 4, p. 671-680, dez. 2015. Disponível em: $\quad<$ http://www.scielosp.org/scielo.php?script $=$ sci arttext\&pid $=$ S2237-96222015000400671\&lng =en\& $\mathrm{nrm}=$ iso $>$. Acesso em: 03 ago. 2016. http://dx.doi. org/10.5123/S1679-49742015000400009.

NORA, C. R. D.; ZOBOLI, E. L. C. P.; VIEIRA, M. Problemas éticos vivenciados por enfermeiros na atenção primária à saúde: revisão integrativa da literatura. Rev. Gaúcha Enferm. Porto Alegre, v. 36, n. 1, p. 112-121, mar. 2015. Disponível em: < http://www. scielo.br/scielo.php?script $=$ sci_arttext $\&$ pid $=$ S198314472015000100112\&lng $=$ en\&nrm $=$ iso $>. \quad$ Acesso em: 01 jun. 2016. http://dx.doi.org/10.1590/19831447.2015.01.48809.

OLIVEIRA, A. M. Problemas éticos vivenciados por enfermeiros e médicos na estratégia saúde da família. 2013. 340 f. Tese (Doutorado em Bioética) - Faculdade de Medicina da Universidade do Porto, Portugal.

PARIZ, J.; MENGARDA, C. F.; FRIZZO, G. B. A atenção e o cuidado à gravidez na adolescência nos âmbitos familiar, político e na sociedade: uma revisão da literatura. Saúde soc., São Paulo, v. 21, n. 3, p. 623-636, set. 2012. Disponível em: $\quad<$ http://www.scielo.br/scielo.php?script $=$ sci arttext\&pid $=$ S0104-12902012000300009\&lng $=\mathrm{en} \&$ $\mathrm{nrm}=$ iso $>$. Acesso em: 24 jul. 2016. http://dx.doi. org/10.1590/S0104-12902012000300009.

PICCININI, C. A.; SILVA, R. A. N. A ação dos agentes comunitários de saúde e o trabalho vivo em ato. Trab. educ. saúde, Rio de Janeiro, v. 13, n. 2, p. 361-379, ago. 2015. Disponível em: <http://www. 
scielo.br/scielo.php?script $=$ sci_arttext\&pid $=$ S1981$77462015000200361 \& \operatorname{lng}=$ en\&nrm $=$ iso $>. \quad$ Acesso em: 03 ago. 2016. http://dx.doi.org/10.1590/1981-7746$\operatorname{sip} 00052$.

PIRES, D. E. P. et al. Consolidação da legislação e ética Profissional. Florianópolis: COREN-SC, 2013. 132 p.

PRATI, L. E.; COUTO, M. C. P. P.; KOLLER, S. H. Famílias em vulnerabilidade social: rastreamento de termos utilizados por terapeutas de família. Psic.: Teor. e Pesq., Brasília, v. 25, n. 3, p. 403-408, set. 2009. Disponível em: $\quad<$ http://www.scielo.br/scielo.php?script $=$ sci_ arttext\&pid $=$ S0102-37722009000300014\&lng $=$ en $\&$ $\mathrm{nrm}=$ iso $>$. Acesso em: 21 jul. 2016. http://dx.doi. org/10.1590/S0102-37722009000300014.

SANTOS, B. R. L. et al. Bioética e o processo de trabalho do Enfermeiro. In: LOCH, J. A.; GAUER, M. C. (Org.). Bioética, interdisciplinaridade e prática clínica. Porto Alegre: EDIPUCRS, 2008. 414p.

SANTOS, C. W.; FARIAS FILHO, M. C. Agentes Comunitários de Saúde: uma perspectiva do capital social. Ciênc. saúde coletiva, Rio de Janeiro, v. 21, n. 5, p. 1659-1668, maio 2016. Disponível em: < http://www. scielo.br/scielo.php?script $=$ sci_arttext\&pid $=$ S1413$81232016000501659 \& \operatorname{lng}=$ en\&nrm $=$ iso $>$. Acesso em: 03 ago. 2016. http://dx.doi.org/10.1590/141381232015215.23332015 .

SCHLITHLER, A. C. B.; CERON, M.; GONÇALVES, D. A. Famílias em situações de vulnerabilidade social. Especialização em Saúde da Família. Módulo Psicossocial, 2016, 69 p.

SCHAEFER, R.; JUNGES, J. R. A construção da competência ética na percepção de enfermeiros da Atenção Primária. Rev. Esc. Enferm USP, v. 48, n. 2, p. 329-34, 2014. DOI: 10.1590/S0080-623420140000200019.

SOUZA JUNIOR, A. P.; MISMITO, G. Z.; ARRUDA, M. F. Avaliação do Programa de Saúde da Família no município de Catanduva - SP. Saúde e Pesqui., v. 5, n. 3, p. 525-531, set./dez. 2012.

TOlOMEU, J. S. O.; FERREIRA, P. A. A.; REIS, A. P.; FERNANDES, D. R. F.; OLIVEIRA, L. C. Ações de educação em saúde para agentes comunitários de saúde. Rev Universidade Vale do Rio Verde, Três Corações, v. 11, n. 1, p. 40-49, 2013.

VIDAL, S. V.; GOMES, A. P.; MAIA, P. M.; GONÇALVES, L. L.; RENNÓ, L.; MOTTA, L. C. S.; SIQUEIRA-BATISTA, R. A bioética e o trabalho na estratégia saúde da família: uma proposta de educação. Rev. bras. educ. med. Rio de Janeiro, v. 38, n. 3, p. 372-380, set. 2014. Disponível em: $\quad<$ http://www.scielo.br/scielo.php?script $=$ sci arttext $\&$ pid $=$ S0100-55022014000300012\&lng $=$ en\& $\mathrm{nrm}=$ iso $>$. Acesso em: 28 nov. 2015. http://dx.doi. org/10.1590/S0100-55022014000300012.

ZOBOLI, E. L. C. P. Enfermeiros e usuários do Programa Saúde da Família: contribuições da bioética para reorientar esta relação profissional. Acta paul. enferm. São Paulo, v. 20, n. 3, p. 316-320, set. 2007. Disponível em: $\quad<$ http://www.scielo.br/scielo.php?script $=$ sci arttext\&pid $=$ S0103-21002007000300012\&lng $=$ en $\& \mathrm{nrm}=\mathrm{iso}>$. Acesso em: 25 jan. 2016. http://dx.doi. org/10.1590/S0103-21002007000300012.

Recebido em: 25 de julbo de 2016 Versão final recebida em: 22 de agosto de 2016 Aceito em: 26 de agosto de 2016 